\title{
Educação do Campo: apropriação pelas professoras de uma escola de assentamento
}

\author{
Delma Rosa dos Santos Bezerra'; https://orcid.org/0000-0003-0036-8019
}

Ana Paula Soares da Silva1; https://orcid.org/0000-0002-0212-2402

\begin{abstract}
Resumo
Este artigo tem como objetivo identificar os elementos mediadores limitadores do processo de apropriação da política da Educação do Campo na visão de cinco professoras de uma escola localizada em assentamento da reforma agrária. O referencial teórico-metodológico adotado foi o da psicologia histórico-cultural. Os instrumentos utilizados para a obtenção do material empírico foram: observações da sala de aula e duas entrevistas semiestruturadas com cinco professoras. No tratamento dos dados, buscou-se: entender os sentidos e significados sobre Educação do Campo e mapear os aspectos dessa política significados como mediadores limitadores do processo de apropriação da política de Educação do Campo. Os resultados apontaram que os aspectos significados como elementos mediadores limitadores do processo de apropriação são: a formação e a orientação para o trabalho na perspectiva da Educação do Campo; a relação com os gestores educacionais; a relação com o projeto político pedagógico e o currículo; a relação com as práticas pedagógicas.
\end{abstract}

Palavras-chave: Professores; população rural; conhecimento.

\section{Field Education: appropriation by teachers of a settlement school}

\begin{abstract}
This article aims to identify the mediating elements limiting the process of appropriation of the Field Education policy by five teachers from a school located in the agrarian reform settlement. The theoretical-methodological framework adopted was that of historical-cultural psychology. The instruments used to obtain the empirical material were: classroom observations and two semistructured interviews with five female teachers. In the treatment of data, we have sought to understand the meanings and meanings of Field Education and to map the aspects of this policy meant as mediators limiting the process of appropriation of the Field Education policy. The results pointed out that the aspects signified as limiting mediating elements of the appropriation process are: training and orientation to work from the Field Education perspective; the relationship with educational managers; the relationship with the political pedagogical project and the curriculum; the relationship with pedagogical practices.
\end{abstract}

Keywords: Docentes; rural population; knowledge.

\section{Educación del Campo: apropiación por las profesoras de una escuela de asentamiento rural}

\begin{abstract}
Resumen
En este artículo se tiene como objetivo identificar los elementos mediadores limitadores del proceso de apropiación de la política dela Educación del Campo por cinco profesoras de una escuela ubicada en asentamiento de la reforma agraria. El referencial teórico metodológico adoptado fue el de la psicología histórico-cultural. Los instrumentos utilizados para la obtención de material empírico fueron: observaciones de la sala de clase y dos entrevistas semiestructuradas con cinco profesoras. En el tratamiento de los datos, se buscó: entender los sentidos y significados sobre Educación del Campo y mapear los aspectos de esa política significados como mediadores limitadores del proceso de apropiación de la política de Educación del Campo. Los resultados apuntaron que los aspectos significados como elementos mediadores limitadores del proceso de apropiación son: la formación y la orientación para el trabajo en la perspectiva de la Educación del Campo; la relación con los gestores educacionales; la relación con el proyecto político pedagógico y el currículo; la relación con las prácticas pedagógicas.
\end{abstract}

Palabras clave: Maestros; población rural; conocimiento.

1 Universidade de São Paulo - Ribeirão Preto - SP - Brasil; delmarsb@ffclrp.usp.br; apsoares.silva@gmail.com 


\section{Introdução}

A educação em contextos rurais, no Brasil, tem uma história na qual os direitos das populações do campo foram amplamente negados. Foram séculos de marginalização durante os quais os governantes ignoraram, em termos legais e políticos, os moradores do campo (Queiroz, 2011). Esse cenário só sofreu alteração significativa no final da década de 1980 e início de 1990, quando o país viveu o processo de democratização e os movimentos sociais começaram a pautar a Educação dos povos do campo como um direito (Souza, 2008; Nascimento, 2009).

As discussões e os debates em torno da Educação do Campo acentuaram-se com a aprovação da Constituição de 1988, que consolidou o compromisso do Estado e da sociedade brasileira em promover educação para todos, garantindo o direito e o respeito a uma educação adequada às singularidades culturais e regionais. Segundo Caldart (2009a), "nascia ali a perspectiva da construção de uma Educação do Campo, livre do jugo das elites" (p.140).

Contudo, o movimento por uma Educação do Campo só começou a ser pautado na agenda política do país com a realização, em 1997, do Enera (Encontro Nacional de Educadoras e Educadores da Reforma Agrária), em que foram amadurecidas as ideias sobre a necessidade de gestar uma nova escola para as populações do campo (Caldart, 2009b; Souza, 2008; Leite, 2002).

Para o amadurecimento da concepção da Educação do Campo como direito e como política pública, contribuíram a Lei de Diretrizes e Bases da Educação n 9.394/96 (LDB 9.394/96, 1996) e o movimento nacional "Por Uma Educação Básica do Campo". A LDB, pela primeira vez, explicitou a especificidade e a diferenciação quanto à oferta de educação básica para a população rural (Souza, 2008). O movimento "Por uma Educação Básica do Campo" surgiu no final da década de 1990 e foi constituído por movimentos sociais e sindicais do campo e por pesquisadores das universidades (Fernandes, Cerioli, \& Caldart, 2009).

Um marco fundamental no processo de consolidação da Educação do Campo como política pública foi a aprovação, em 2002, na Câmara de Educação Básica do Conselho Nacional de Educação, das Diretrizes Operacionais para a Educação Básica nas Escolas do Campo (Resolução n 1 CNE, 2002). As Diretrizes foram compreendidas como divisor de águas entre uma visão de educação para o chamado meio rural e a adoção de um novo ideário político; elas incorporam a expressão Educação do Campo e evidenciam o valor da educação para as populações do campo e a necessidade de considerá-los protagonistas de seu processo educacional (Leal, 2012).

Outras iniciativas importantes de construção da Educação do Campo como política pública foram: a instituição, no primeiro semestre de 2003, no Ministério da Educação, do Grupo de Trabalho Permanente sobre Educação do Campo, responsável por levantar instrumentos para a construção de uma política pública de educação do campo; a elaboração do documento "Referência para uma Política Pública para Educação do Campo”, em 2003, que teve como objetivo apresentar um conjunto de informações e reflexões para subsidiar a formulação de políticas públicas de Educa- ção do Campo em âmbito nacional;a criação, em 2004, e a reestruturação, em 2012, da Secretaria de Educação Continuada, Alfabetização, Diversidade e Inclusão do Ministério da Educação, à qual se vinculava a Coordenação Geral do Campo. Também foi significativa para esse movimento de construção da identidade da Educação do Campo a reformulação, em 2009, das Diretrizes Curriculares Nacionais da Educação Infantil (Resolução CNE/CEB n 5/2009, 2009), que regulamentaram, pela primeira vez, a articulação entre normativas da Educação do Campo e da Educação Infantil (Silva, Pasuch, \& Silva, 2012).

A aprovação pelo Ministério da Educação, em 2006, na Secretaria de Educação Continuada, Alfabetização e Diversidade, do Programa de Apoio à Formação Superior em Licenciatura em Educação do Campo (Procampo), a divulgação da Resolução $n^{\circ} 2$, de abril de 2008, que estabelece diretrizes complementares, normas e princípios para o estabelecimento da política da Educação do Campo (Resolução CNE/CEB n² do CNE, 2008), a publicação do decreto 7.352 que dispõe sobre a Política da Educação do Campo e o Pronera (Programa Nacional de Educação na Reforma Agrária) (Decreto $n^{\circ} 7.352,2010$ ) e a criação, em 2012, do Programa Nacional de Educação do Campo (Pronacampo), vinculado à Secadi, do MEC, foram ações e programas essenciais na elaboração da política da Educação do Campo.

Destaca-se,desses programas, o Procampo, que foi criado com o objetivo de apoiar a implementação de cursos regulares de Licenciatura em Educação do Campo voltados para a formação de educadores das escolas do campo. Apesar de o Procampo ser uma política pontual e não contínua, ele é considerado uma política inovadora tanto no domínio das políticas educacionais como no da formação docente porque contribuiu para o fortalecimento da qualificação do professor que atua no campo(Costa \& Monteiro, 2012).

A instituição da Educação do Campo como uma política pública específica para os povos do campo por meio desses marcos legais, programas governamentais e ações dos movimentos sociais, propõe um projeto e uma identidade para as escolas do campo completamente diferentes do que estava posto até então. O chamado paradigma da Educação do Campo, com o qual se compactua nesta pesquisa, defende uma educação que, além de considerar as especificidades da identidade, cultura, modos de produção e de vida dos povos do campo, seja oferecida no lugar onde moram e construída com sua participação (Arroyo \& Fernandes, 1999; Souza, 2008; Fernandes \& cols., 2009).Os discursos em torno da Educação do Campo destacam a importância dos professores na construção dessa identidade nas unidades escolares do campo (Caldart, 2002).

A Lei de Diretrizes e Bases da Educação 9394/96 e as Diretrizes Operacionais para a Educação Básica nas Escolas do Campo (Resolução CNE/CEB n 1, 2002) avançaram no aspecto da formação dos professores: a primeira postula que a formação dos professores da educação infantil e da primeira etapa do ensino fundamental aconteça em nível superior; a segunda oferece orientações de como deve ser a formação inicial e continuada dos professores das escolas 
do campo. Apesar dessas normativas, para os professores têm sido um desafio o processo de implementação da política da Educação do Campo nas escolas (Souza, 2008).

Diversos estudos têm apontado que parte deste desafio tem relação com a formação inicial e continuada dos professores da escola do campo (Saggiomo, Azevedo, \& Machado, 2012; Bernardi, Pelinson, \& Santin, 2014; Locks, Graupe, \& Pereira, 2015; Conte, \& Ribeiro, 2017). Para Arroyo (2007), no centro deste debate, está a dificuldade que os governos têm de elaborar políticas de formação voltadas especificamente para os professores que atuam no campo. Segundo o autor, historicamente, as políticas de formação foram pensadas a partir do paradigma da escola urbana. A consequência dessa forma de se fazer política educacional é a secundarização das políticas para o campo.

Molina e Antunes-Rocha (2014) também ressaltam a importância de compreender o professor e sua formação para o desenvolvimento da política da Educação do Campo. Elas destacam que o país ainda precisa superar vários obstáculos para consolidar a formação do professor da escola do campo como política pública capaz de garantir a construção de uma escola vinculada à luta das populações do campo.

Além da formação de professores, outros estudos apontam que, para a política Educação do Campo se consolidar nas escolas, é preciso fazer avançar a relação com a comunidade (Saggiomo, Azevedo, \& Machado, 2012), bem como garantira representatividade das populações do campo nos diversos âmbitos da gestão dessa política (Santos \& Silva,2016), construir currículos que contemplem a diversidade das escolas do campo, trabalhar na formulação de materiais adequados e melhorar condições estruturais da escolas do campo (Locks \& cols., 2015).

O cenário das políticas da Educação do Campo no país, bem como os dados das pesquisas com foco no professor, têm sinalizado a importância de conhecer mais sobre esse profissional e sobre os elementos que estão implicados na sua relação com a política que vem sendo elaborada pelos movimentos sociais e positivada nas normativas educacionais brasileiras.

Neste sentido, o trabalho tem como objetivo identificar os elementos mediadores limitadores da apropriação da política da Educação do Campo por cinco professoras de uma escola localizada em assentamento da reforma agrária. Acredita-se que levantar e compreender esses elementos sejam relevantes na identificação de entraves aos desdobramentos necessários para seu avanço. A fragilidade dessa política, que corre riscos no cenário político atual, demanda ainda mais que conhecimentos sejam produzidos a fim de contribuir para sua resistência e continuidade.

\section{Método}

\section{Participantes}

Participaram do estudo cinco professoras de uma escola localizada em um assentamento rural de reforma agrária, que atende cerca de 60 alunos da Educação Infantil, Ensino Fundamental I e Educação de Jovens e Adultos. Quatro professoras são polivalentes e atuam na primeira etapa do Ensino Fundamental; uma é especialista e atua nas primeira e segunda etapas do Ensino Fundamental, nas disciplinas de arte e educação física. Três são concursadas e estão trabalhando há quase quatro anos na instituição e duas são celetistas e trabalham há menos de um ano na escola. Quatro têm formação em nível superior e uma em nível médio. Nenhuma professora tem formação inicial específica para atuar nas escolas do campo; quatro cursaram aperfeiçoamento que discutia a construção de projetos políticos pedagógicos de escolas do campo. Para preservar a identidade das professoras, os nomes das participantes foram substituídos por nomes fictícios.

\section{Instrumentos}

Os dados foram construídos a partir de duas entrevistas semiestruturadas e observação de 14 dias dos espaços, das dinâmicas e das rotinas das professoras. As entrevistas foram estruturadas a partir dos pressupostos de Freitas (2002), e as observações, nos de Nascimento (2014) e Lima (2012).

\section{Procedimento de coleta de dados}

Inicialmente, a pesquisa foi submetida e aprovada pelo Comitê de Ética e Pesquisa com Humanos sob o número de protocolo066759/2013. Após a aprovação, os primeiros contatos com as professoras foram feitos por meio de telefonema. A diretora da escola na qual as professoras trabalhavam foi a mediadora entre a pesquisadora e as professoras. Numa primeira oportunidade, o projeto foi apresentado à diretora e, posteriormente, às professoras. O Termo de Consentimento Livre Esclarecido - TCLE - foi apresentado pela pesquisadora e assinado pelas professoras. A coleta de dados foi realizada pela própria pesquisadora, no período de quatro meses.

\section{Procedimento de Análise}

A análise dos dados fundamentou-se no referencial teórico-metodológico da psicologia histórico-cultural de Lev Semionovitch Vigotsky.

O estudo apoiou-se no conceito de mediação de Vigotsky (2007). Para o estudioso, a mediação é um processo em que elementos, tanto de ordem material ou simbólica, intervêm em uma relação (Oliveira, 1993). Esses elementos mediadores são denominados como instrumentos e signos. Os instrumentos são elementos externos ao indivíduo que estão no âmbito social e têm a função de promover e controlar mudanças no objeto, na natureza e, consequentemente, acabam por promover alterações no próprio homem. 
O signo é de ordem psicológica; ele representa objetos, situações, eventos etc. que visam dirigir e controlar ações psicológicas voltadas para orientar o sujeito (Oliveira, 1993). A palavra é um exemplo de signo que medeia os processos de apropriação dos elementos sociais pelo homem. Pela palavra o homem acessa e se apropria de fatos, objetos, regras, legislações e conhecimentos (Pino, 1992; Rego, 1995; Veer \& Valsiner, 1999). Pela palavra, pensamento e fala mostram-se como inseparáveis, motivo pelo qual o significado da palavra é a unidade de análise que permite a não fragmentação da investigação dos processos psicológicos. Significado e sentido são categorias centrais na perspectiva vigotskiana: a primeira, mais estável, relacionada ao processo de generalização; a segunda, fluida e dependente dos contextos e usos: o sentido é "a soma de todos os eventos psicológicos evocados em nossa consciência graças à palavra", e o significado é "uma dessas zonas de sentido, a mais estável, coerente e precisa” (Vigotsky, 2010, p. 465).

Tendo como bases o conceito de mediação de Vigotsky (2007) e o interesse nos aspectos que restringem a apropriação da política de Educação do campo pelos professores, trabalhou-se com a noção de elementos mediadores limitadores. Procurou-se identificar os sentidos e significados com os quais as professoras interagiam e que dificultavam o processo de apropriação da política da Educação do Campo pelas professoras.

O conceito de apropriação foi tomado como um processo de identificação, noção que se remete ao que se tornou próprio do sujeito, isto é, aquilo sobre o qual o sujeito imprime uma ação e se reconhece no produto (Alencar \& Freire, 2007). Na perspectiva vigotskiana, "tornar-se próprio implica fazer e usar instrumentos numa transformação recíproca de sujeitos e objetos, constituindo modos particulares de trabalhar/produzir" (Smolka, 2000, p. 28). No tratamento e análise do material, construiu-se um mapa em que (a) identificaram-se os sentidos e significados sobre a política da Educação do Campo; (b) categorizaram-se os sentidos e significados que se caracterizavam como limitadores da política; (c) buscou-se identificar a que aspectos da política esses sentidos e significados se referiam. Após o delineamento desse mapa, foram definidos os eixos de análise: a formação e a orientação para o trabalho na perspectiva da Educação do Campo; a relação com os gestores educacionais; a relação com o projeto político-pedagógico e o currículo; a relação com as práticas pedagógicas.

\section{Resultados e Discussão}

\section{A formação e a orientação para o trabalho na perspectiva da Educação do Campo}

A maioria das professoras, no momento de introdução na escola do campo, não contou com um processo que possibilitasse a mediação potencializadora em relação à política de Educação do Campo.
Pesquisadora- E como os professores são orientados pela escola para desenvolver o ensino dentro da concepção da Educação do Campo?

Maria- Orientação é dos cursos que a gente fala sobre o (nome do sistema apostilado), que eles falam as maneiras de trabalhar com apostila. (...)

Pesquisadora- E vocês têm cursos oferecidos pela secretaria, direcionado para Educação do Campo?

\section{Maria - Não direcionado para Educação do Campo.}

Apesar de quase todas as professoras participantes da pesquisa terem formação em nível superior (apenas uma não era graduada, mas estava em processo de formação) - o que evidencia um avanço em relação à formação encontrada em outras pesquisas(Molina, 2010) -, nenhuma havia cursado licenciatura específica para atuação nessas escolas.

A ausência da formação e de orientação acontecia tanto no âmbito da escola como da Secretaria Municipal de Educação. Atuava, como agravante desse processo, a adoção, pelo município, de um material didático apostilado, comprado de um sistema privado de ensino. Fazia parte do pacote a formação para atuação com o material apostilado, cujos princípios pedagógicos conflitavam com os da Educação do Campo.

Dessa forma, a formação por meio do material apostilado atuava de modo complementar à ausência da formação específica, no sentido de restringir as possibilidades de aproximação das professoras à política e aos princípios da Educação do Campo.

É inconteste que a formação é um instrumento essencial para o professor se apropriar das políticas, legislações, discussões, dos conceitos, dos saberes e das práticas da área de atuação. No caso da Educação do Campo, a formação adquire uma relevância ainda maior porque é por meio dela que se devem garantir os conhecimentos específicos necessários para atuação nas escolas do campo, que vão além dos conhecimentos gerais da profissão docente. A ausência da formação específica, seja inicial ou em serviço, configura-se uma interferência direta no processo de apropriação das professoras da política Educação do Campo - uma vez que ela é produto das ações dos responsáveis por promover essa formação - e limita o processo de apropriação dos princípios e práticas propostos pela Educação do Campo. É limitador em especial por ocupar o espaço e o tempo da formação com outras demandas que não convergem com os objetivos da Educação do Campo. Para Bernardi e cols. (2014) sem uma boa formação em serviço os professores das escolas do campo tendem a se aproximar mais das discussões sociológicas da Educação do Campo, não evoluindo para uma discussão crítica epistemológica. Sem esse avanço, os professores não têm acesso a conhecimentos e debates relevantes da área que funcionam como mediadores potencializadores que ajudam na ressignifica- 
ção de sentidos da escola, do campo e dos sujeitos do campo e, consequentemente, impulsionam a consolidação da política Educação do Campo numa perspectiva mais ampla e adequada à realidade das escolas do campo.

\section{A relação com os gestores educacionais}

A relação dos gestores municipais com as professoras se caracterizava pela omissão.

\begin{abstract}
Maria - O que eu gostaria que aqui acontecesse, que tivesse mais empenho, porque eu sozinha não vou conseguir fazer. Por parte dos órgãos competentes, órgãos maiores, eles têm que se disponibilizar mais, eles têm que dar mais apoio para gente, dar mais incentivo, sabe, mais capacitação para gente trabalhar melhor, pôr pessoas que realmente saibam mexer com a escola do campo, saibam trabalhar com a escola do campo, que dê essa formação. As escolas do campo devem ser assim: ter uma coordenação diferenciada, sabe? Onde o diretor da escola, por exemplo, não ficasse só em busca, "ai eu tenho que ver lá na cidade o que vai ser feito, ai eu vou ver com fulano se pode". Não, eu acho que tinha que ter uma base central para escola, ter uma Secretaria de Educação do Campo, que ela realmente fosse buscar o que precisa dentro da escola...
\end{abstract}

O envolvimento dos gestores da política da Educação no município foi significado como não suficiente para subsidiá-las no trabalho dentro da perspectiva da Educação do Campo, produzindo sentimentos de estarem desassistidas em suas demandas e particularidades.

A apropriação da política estava assim mediada pelo sentido de que a Secretaria de Educação era negligente. A omissão das instâncias gestoras, além de não respaldar o trabalho das professoras, deixava sob suas responsabilidades as iniciativas de implantação de ações condizentes com a política de Educação do Campo. Essa condição transformava o processo de apropriação em um esforço individual e não baseado em práticas coletivamente legitimadas; atuar ou não de acordo com a política de Educação do Campo, nessa perspectiva, passa a ser uma decisão meramente pessoal.

A secundarização da política da Educação do Campo por parte dos gestores no município, segundo as professoras, ocorria como resultado da priorização da oferta padronizada de educação, tanto em área urbana como rural.

Essa ausência reflete o silenciamento histórico do poder público em relação à educação das populações do campo (Souza, 2012; Leite, 2002). Mostra ainda que, embora haja avanços no âmbito da elaboração das políticas nas últimas décadas (Souza, 2008; Nascimento, 2009; Marcon, 2012), no âmbito dos municípios essas políticas ainda não produziram impactos significativos.

Tanto a omissão quanto a secundarização da política de Educação do Campo estavam relacionadas à carência de orientação e de formação dos gestores para administrar a política da Educação do Campo. A cadeia de formação, necessária para mediar as políticas gestadas em âmbito nacional, não existia ou não se efetivava.

Esse aspecto indica que a fragilização do processo de apropriação das professoras está vinculada à fragilização dos sistemas e das redes de ensino, especialmente daqueles que não têm autonomia e estrutura suficientes para manter profissionais especialistas no subsídio ao desenvolvimento das políticas nos municípios (Medeiros, 2014).

Segundo Leal (2012), que também estudou o processo de apropriação da política da Educação do Campo com o foco no nível de apropriação dos responsáveis pela política, o nível de apropriação desses sujeitos reflete as relações entre a política nacional e o modo como a política é efetivada na localidade,

Evidencia-se assim conflito entre a política nacional de Educação do campo, que propõe reelaboração e ressignificação das práticas estabelecidas, e a não qualificação dos gestores.

\section{A relação com o projeto político pedagógico e o currículo}

Pesquisadora - E como é que foi essa participação na construção do projeto político-pedagógico?

Sofia - Já veio pronto da outra escola e a gente só inseriu algumas coisas que a gente entre aspas achava que era o correto. Depois a gente começou a enxergar que não é bem assim.

Pesquisadora: E como que é o currículo da escola? Sofia - É igual o currículo da cidade.

Pesquisadora - E como é o currículo da cidade?

Sofia - É português, matemática, história, geografia, ciências, é o que o governo manda, são as diretrizes (gerais) do MEC.

Havia uma política de terceirização da construção do projeto político pedagógico e do currículo que era significada como dificultando a participação das professoras em seu processo de apropriação. A relação com o projeto político pedagógico e o currículo era, portanto, sentida como superficial, uma vez que não estabelecia afinidade e autoria com os documentos orientadores da prática. Não existiam espaços e tempos para discussão do projeto político pedagógico e do currículo, nem formação, orientação ou autonomia. O currículo e o projeto político pedagógico funcionavam limitando o processo de apropriação da Educação do Campo pelas professoras.

Outra significação referente ao projeto político pedagógico e ao currículo dialoga com o que foi apontado no estudo de Damasceno e Beserra (2004): há uma distância 
da escola em relação às demandas e à realidade de sua população. Na verdade, o currículo não era próprio da e para a escola do campo. Ele desconsiderava o contexto e a realidade socioeconômica e cultural do assentamento da escola (Saggiomo \& cols., 2012; Santos \& Silva, 2016).

Sofia - Aqui essa escola do campo não vive a realidade daqui, ela vive a realidade da cidade...

\section{Pesquisadora: Porque você acha que não vive?}

Sofia - Pelo apostilado, que a gente é obrigado a seguir. Tudo aqui é padronizado com a cidade, por mais que a escola tenta ter uma identidade própria, acaba não tendo.

A não autoria das professoras no projeto político pedagógico e a distância em relação à comunidade associavam-se à força do sistema apostilado no município, que seguia o exemplo de vários outros municípios paulistas de pequeno porte que passaram a adotar esses sistemas a partir dos anos 2000 (Adrião, Garcia, Borghi, \& Arelaro, 2009). Embora exista um Plano Nacional do Livro Didático do Campo (PNLD do Campo), criado em 2013 pelo Ministério da Educação, essa política mostrou-se não ser suficiente para promover a apropriação pelas professoras dos princípios e práticas da Educação do Campo e nem mesmo para fazer frente às investidas dos sistemas privados de ensino e aos significados que sobre eles foram construídos socialmente.

A presença do sistema apostilado, que disponibilizava formação técnica para o uso do material, gerava nas professoras uma sensação de confiança e segurança para desenvolver o ensino. As professoras, quando tiveram a opção de não mais trabalhar com esse material, apresentada pela Secretaria Municipal de Educação junto com a possibilidade de adotarem o PNLD do Campo, decidiram por não abrir mão do material apostilado do sistema privado; alegaram ainda receio de se diferenciarem em relação às professoras da cidade.

A situação de dependência do material apostilado, articulada com a ausência de formação continuada, implicava aspectos financeiros e ideológicos. As professoras, os representantes da política local e a comunidade escolar adotaram o discurso de que o material oferecia uma qualidade melhor de ensino e aprendizagem aos alunos e suporte técnico-pedagógico para as professoras.

Pavini (2012), que estudou a presença de materiais apostilados numa escola de assentamento, afirma que um dos problemas de ter o trabalho pedagógico da escola do campo orientado por esse tipo de recurso didático é que ele não apresenta conteúdo significativo para a aprendizagem do aluno, o que gera dificuldades para esse processo. Além disso, exige um esforço muito grande do professor para adaptar constantemente o material às necessidades atinentes às populações do campo.

Assim como Pavini (2012), este estudo verificou que a presença do sistema apostilado nas escolas do campo acabou por onerar o trabalho do professor, pois este precisava se formar e se apropriar não só do que concerne ao material didático como também do que afeta a perspectiva da Educação do Campo.

\section{A relação com as práticas pedagógicas.}

Pesquisadora - Dá um exemplo do que você já fez?

Sofia - Eu até tentei fazer uma horta, mas na época do calor as plantinhas acabaram morrendo, não aguentaram mesmo porque eu até pedi ajuda de alguns pais, mas não deu muito certo, e aí não foi para frente.

Pesquisadora - Que você já fez que você considera assim, ah, isso é bem educação do campo?

Maria - O plantio, a horta suspensa. O plantio foi muito favorável, sabe, porque as crianças realmente elas plantavam, elas cuidaram das plantas ao redor, sabe. Para eles, era assim, muito gostoso, eles saírem lá fora para regar aquelas plantas. Elas falavam: "hoje é dia da gente regar as plantas, nossa".

As práticas mais significadas pelas professoras como representativas daquelas vinculadas à Educação do Campo foram aquelas que tinham relação direta com a natureza, com a terra e eram desenvolvidas fora da sala de aula, por exemplo, o plantio e o cultivo de hortas.

As iniciativas de aproximação ao que propõe a política de Educação do Campo não eram consensuais e nem sistemáticas. As profissionais, em momentos esporádicos, próximos a datas comemorativas, propunham atividades que tinham como objetivo colocar a criança em contato com a natureza ou, como pano de fundo, questões do meio ambiente e do campo. As atividades que tinham alguma relação com o campo - por exemplo, o cultivo de uma horta - eram significadas como meio ou como fim apenas para ensinar conteúdos.

As professoras significaram que era o trabalho com atividades atinentes ao dia a dia do trabalho do homem do campo que garantia à aproximação à Educação do Campo. O movimento era de tentar reproduzir, na escola, a experiência que o aluno trazia do campo, mais especificamente, o que elas imaginavam ser esta experiência.

Para elas, essas práticas deveriam, de alguma forma, antecipar para o aluno os conhecimentos e as vivências com os quais teriam contato na vida cotidiana do campo. Contudo, essa prática de antecipação e reprodução das experiências na escola do campo era feita sem problematização ou discussão dos contextos políticos, econômicos e sociais. O foco ficava somente no fazer, revelando uma concepção de Educação do Campo estritamente pragmática, o que restringia o seu significado. As Diretrizes Operacionais da Educação Básica da Escola do Campo (Resolução, 2002), no artigo $5^{\circ}$, dizem que as propostas pedagógicas devem respeitar as diferenças e contemplar as diversidades do campo em todos os seus aspectos. M. Souza (2012) afirma 
que a prática pedagógica deve ser uma prática social que vise à formação humana e transformação social.

\section{Considerações Finais}

A partir da análise dos quatro aspectos da relação das professoras com a política da Educação do Campo, verificou-se que os dados da pesquisa dialogam com os estudos que problematizam a ausência de formação específica para atuação nas escolas do campo (Correia \& Rocha, 2013), a terceirização do currículo e do projeto político pedagógico (Locks \& cols., 2015) e a forma como os gestores interagem com a escola do campo (Santos \& Silva, 2016). Esses elementos precarizam as condições de trabalho e comprometem as atividades dessas professoras, entre outras coisas, porque limitam e fragilizam a apropriação que fazem da política da Educação do Campo.

Os mediadores que configuram os significados de cada um desses aspectos refletem-se na relação que as professoras mantêm com as práticas pedagógicas. A aproximação à Educação do Campo é feita de modo estereotipado, carecendo de reflexões que tornem complexos os modos de significação da vida dos sujeitos no campo. É nesse sentido que a horta aparece como ícone de uma apropriação superficial.

Os dados mostram como é difícil construir um paradigma novo de Educação, como se propõe a Educação do Campo, a partir de estruturas, práticas e relações arcaicas. Acredita-se que esse seja talvez o maior desafio da Educação do Campo, uma vez que a oposição a um modelo hegemônico e secularmente consolidado exige a construção de novas hegemonias, de novos significados sobre as melhores formas de educar. Há que se considerar que são múltiplos os mediadores limitadores e que os sentidos e significados produzidos não atuam isoladamente ou de forma linear. Ao contrário, como um emaranhado, estabelecem entre si relações complexas, complementando-se com força na manutenção de uma escola tradicional e refratária a mudanças, (re)produzindo-se por meio de práticas descontextualizadas ou generalizadas e fragilizando o processo de apropriação da política de Educação do Campo pelas professoras. Assim, os desafios para consolidar essa política educacional são grandes, porque são de diversas ordens os mediadores limitadores que se interpõem no cotidiano do professor (dificultando sua apropriação e, consequentemente, atuação), no interjogo com o cotidiano dos processos de gestão.

A pesquisa traz, assim, dados que contribuem para o aprofundamento e o desenvolvimento das discussões sobre o futuro da política Educação do Campo em diferentes âmbitos. O primeiro diz respeito ao processo de orientação e acompanhamento dos municípios na apropriação e implementação das políticas da Educação do Campo. A pesquisa instiga novos estudos para que sejam conhecidos os caminhos pelos quais as políticas e programas nacionais da Educação do Campo chegam aos municípios, seus processos de acompanhamento e o tipo de orientação e suporte técnico. Entender os desafios postos nesse percurso pode ajudar a avançar o intercâmbio da política com a gestão nos municípios e as práticas no interior das instituições, de modo a fazer frente às investidas dos sistemas apostilados de ensino. Esses sistemas, se reconhecidamente impactam negativamente a autonomia dos professores no meio urbano, apresentam prejuízos adicionais nas escolas do campo, dado o seu caráter homogeneizador.

O segundo refere-se à importância de reforçar o investimento em políticas de formação inicial e em serviço. Mais que um discurso pela formação, esta é uma exigência quando escutamos professores que atuam nas escolas do campo e nos sensibilizamos aos seus apelos formativos, denunciando a precariedade da formação inicial e continuada para lidar com as especificidades do contexto e da vida social, econômica e política dos sujeitos do campo.

O terceiro contempla o direito das populações do campo à educação que considere sua cultura, identidade, história, modos de produção e de vida. Um professor que não se apropria daquilo que é específico e definidor da identidade da escola do campo não pode se constituir, ele mesmo, como instrumento de transformação das práticas no interior das escolas do campo; portanto, não pode garantir a plenitude do direito à educação dos povos do campo na concretude da sua atuação diária com seus alunos.

Conclui-se, por fim, que a identificação de mediadores limitadores não denuncia apenas uma fragilidade no processo de apropriação da política da Educação do Campo pelas professoras, mas que essa fragilidade tem relação com o fato da política da Educação do Campo talvez dispor dos mesmos, ou até mais precarizados, parcos e frágeis mediadores presentes na Educação que pretende superar. Isso significa que a política da Educação do Campo precisa questionar, inclusive, os meios pelos quais tem promovido a Educação do Campo no interior das redes de ensino.

\section{Referências}

Adrião, T.; Garcia, T.; Borghi; R.; Arelaro, L. (2009, outubro). Uma modalidade peculiar de privatização da educação pública: a aquisição de "sistemas de ensino" por municípios paulistas. Educação \& Sociedade, 30(108), 799-818. Recuperado: 25 ago. 2016. Disponível: http://www.scielo.br/scielo. php?script=sci_arttext\&pid=S0101-73302009000300009.

Alencar, H. F.; Freire, J. C. (2007). O lugar da alteridade na psicologia ambiental. Revista Mal-Estar e Subjetividade, 7(2), 305-328. Recuperado: 20 mai. 2016; Disponível: http://pepsic.bvsalud.org/ pdf/malestar/v7n2/05.pdf.

Arroyo, M. G. (2007). Políticas de formação de educadores(as) do campo. Cadernos CEDES, 27(72), 157-176. Recuperado: 21 set. 2016. Disponível: http://www.scielo.br/pdf/ccedes/v27n72/ a04v2772.pdf.

Arroyo, M. G.; Fernandes, B. M. (1999). Articulação Nacional Por uma Educação Básica do Campo. (Coleção Por uma Educação 
Básica do Campo, $n^{\circ}$ 2). Brasília, DF: Articulação Nacional Por uma Educação Básica do Campo.

Bernardi, L. T. M. S.; Pelinson, N. C. F.; Santin, R., (2014). O desafio de ser professor na escola do campo: contexto da casa familiar rural Santo Agostinho. Revista Reflexão e Ação, 22 (2), 120-142. Recuperado: 21 abr. 2016. Disponível: https://online.unisc.br/ seer/index.php/reflex/article/view/5099

Caldart, R. S. (2002). Pedagogia do Movimento Sem Terra (3a Ed.). São Paulo, SP: Expressão Popular.

Caldart, R. S. (2009a). Por uma Educação do Campo: traços de uma identidade em construção. In: Arroyo, M.; Caldart, R. S.; Molina, M. C. (Orgs.), Por uma educação do campo (4a ed., pp. 25-36). Petrópolis, RJ: Vozes.

Caldart, R. S. (2009b). Educação do Campo: Notas Para Uma Análise de Percurso. Trabalho, Educação e Saúde, 7(1), 35-64. Recuperado: 06 mar. 2014. Disponível: http://www.scielo.br/pdf/ tes/v7n1/03.pdf.

Constituição da República Federativa do Brasil de 1988 (1988, 5 de outubro). Brasília: Presidência da República. Recuperado: 21 abr. 2016. Disponível: http://www.planalto.gov.br/ccivil_03/ constituicao/constituicaocompilado.htm.

Conte, I. I.; Ribeiro, M. (2017). Saberes-Fazeres que atravessam a Educação do Campo. Revista Roteiro, 42(1), 201-222. Recuperado: 31 out. 2016. Disponível: http://editora.unoesc.edu. br/index.php/roteiro/article/view/10695/pdf

Correia, R. A. C.; Rocha, S. A. (2013). Formar-se professora do no campo; percepções de licenciadas do campo em memoriais de formação. Revista de Educação da PUC-Campinas, 18(3), 355366 .

Costa, E. M.; Monteiro, A. L. (2012). Procampo: uma política de formação inicial para o docente do campo. In: Leite, U. F., Marin, A. J., Pimenta, S. G., Gomes, M. O.; Reali, A. M. M. R.(Orgs.). Políticas de formação inicial e continuada de professores (1 ${ }^{a}$ ed, pp. 001741-001752.). Araraquara, SP: Junqueira \& Marin. Recuperado: 20 ago. 2016. Disponível: http://www.infoteca.inf. br/endipe/smarty/templates/arquivos_template/upload_arquivos/ acervo/docs/1901p.pdf

Damasceno, M. N.; Beserra, B. (2004). Estudos sobre educação rural no Brasil: estado da arte e perspectivas. Educação e Pesquisa (USP), 30, 73-89.

Decreto $n^{\circ} 7.352$ (2010, 4 de novembro). Dispõe sobre a política de educação do campo e o Programa Nacional de Educação na Reforma Agrária-PRONERA. Brasília: Presidência da República. Recuperado: 21 set. 2016. Disponível: http://www.planalto.gov.br/ ccivil_03/_ato2007-2010/2010/decreto/d7352.htm.

Fernandes, B. M.; Cerioli, P.; Caldart, R. S. (2009). Primeira
Conferência Nacional por uma Educação Básica do Campo. In: Arroyo, M. G.; Caldart, R. S.; Molina, M. C. (Orgs.), Por uma educação do campo (pp. 19-63). Petrópolis: Vozes.

Freitas, M. T. A. (2002). A abordagem sócio-histórica como orientadora da pesquisa qualitativa. Cadernos de Pesquisa, 1(116), 21-40. Recuperado: 22 fev. 2016. Disponível: http://www.scielo.br/scielo. php?script=sci_arttext\&pid=S0100-15742002000200002.

Leal, F. L. A. (2012). Na mão e na contramão da política: a realização da política nacional de educação do campo em municípios do cariri paraibano. Tese de Doutorado em Ciências Sociais, Centro de Humanidades, Universidade Federal de Campina Grande, Campina Grande-PB.

Lei $n^{\circ} 9.394$ (1996, de 20 de dezembro). Estabelece as diretrizes e bases da educação nacional. Brasília: Presidência da República. Recuperado: 22 fev. 2016. Disponível: http://portal.mec.gov.br/ seed/arquivos/pdf/tvescola/leis/lein9394.pdf.

Leite, S. C. (2002). Escola Rural: urbanização e políticas educacionais (2a ed.). São Paulo, SP: Cortez.

Lima, L. P. (2012). A relação entre a Educação Infantil e as famílias do campo. Tese de Doutorado, Faculdade de Filosofia, Ciências e Letras, Universidade de São Paulo, Ribeirão Preto-SP, Brasil.

Locks, G. A.; Graupe, M. E.; Pereira, J. A. (2015). Educação do Campo e direitos humanos: uma conquista e muitos desafios. Revista Conjectura: filosofia e educação, 20(n. especial), 131-154.

Marcon, T. (2012). Políticas de educação do campo: avanços e desafios. Práxis Educativa, 7, 85-105. Recuperado: 24 mai. 2016. Disponível: http://www.redalyc.org/pdf/894/89423377006.pdf.

Medeiros, L. B. (2014). Educação do campo e política educacional brasileira: aproximações e distanciamentos na realidade local. Reflexão e Ação, 22(2), 195-219.

Molina, M. C. (2010). Reflexões Sobre o Significado do Protagonismo dos Movimentos Sociais na Construção de Políticas Públicas de Educação do Campo. In: Molina, M. C. (Org.),Educação do Campo e Pesquisa II (Vol. 1, pp. 137-149). Brasília: NEAD.

Molina, M. C.; Antunes-Rocha, M. I. (2014). Educação do Campo: História, Práticas e Desafios no âmbito das políticas de formação de educadores - reflexões sobre o PRONERA e O PROCAMPO. Revista Reflexão e Ação, 22(2), pp. 220-253. Recuperado: 01 set. 2016. Disponível: https://online.unisc.br/seer/index.php/reflex/ article/viewFile/5252/3689

Nascimento, C. G. (2009). Educação do Campo e Políticas Públicas Para Além do Capital: Hegemonias em Disputas. Tese de Doutorado, Universidade de Brasília, Brasília.

Oliveira, M. K. (1993). Vygosty: aprendizado e desenvolvimento, um processo sócio-histórico. São Paulo, SP: Scipione. 
Pavini, G. C. (2012). O método Sesi de ensino na escola do campo: a controversa chegada do estranho. Dissertação de Mestrado. Centro Universitário de Araraquara, Araraquara, SP.

Pino, A. (1992). As categorias de público e privado na análise do processo de internalização. Educação e Sociedade, (2), 315-327.

Queiroz, J. B. P. (2011). A educação do campo no Brasil e construção das escolas do campo. Revista Nera, 14(18), 37-46. Recuperado: 30 jun. 2016. Disponível: http://www.reformaagrariaemdados.org. $\mathrm{br} / \mathrm{sites} /$ default/files/1347-3845-1-PB.pdf.

Rego, T. C. (1995). Vygotsky: uma perspectiva histórico-cultural da educação. Petrópolis, RJ: Vozes.

Resolução CNE/CEB $n^{\circ} 1$ (2002, 3 de abril). Institui Diretrizes Complementares Diretrizes complementares, normas e princípios para o desenvolvimento de políticas públicas de atendimento da Educação Básica do. Diário Oficial da União. Brasília: Conselho Nacional de Educação.

Resolução CNE/CEB $n^{\circ} 2$ (2008, 28 de abril). Estabelece diretrizes complementares, normas e princípios para o desenvolvimento de políticas públicas de atendimento da Educação Básica do Campo. Brasília: Presidência da República. Recuperado em 21 de junho, 2016, de http://portal.mec.gov.br/secad/arquivos/pdf/ resolucao0208.pdf.

Resolução CNE/CEB n 5 5 (2009, 17 dezembro). Diretrizes Curriculares Nacionais da Educação Infantil. Diário Oficial da União. Brasília: Conselho Nacional de Educação

Saggiomo, T. G.; Avezedo, M. S.; Machado, V. S. (2012). Desafios na realidade educativa do campo; uma abordagem de encontros e desencontros na escola do campo. In: IXAnped SUL, Caxias do Sul, Rio Grande do Sul.
Santos, R. B.; Silva, M. A. (2016). Políticas em Educação do Campo: Pronera, Procampo e Pronacampo. Revista Eletrônica de Educação, 10 (2), 135-144. Doi: http://dx.doi. org/10.14244/198271991549

Silva, A. P.; Pasuch, J.; Silva, J. B. (2012). Educação Infantil do campo. São Paulo, SP: Cortez.

Smolka, A. L. B. (2000). O (im)próprio e o (im)pertinente na apropriação das práticas sociais. Cadernos Cedes, 20(50), 26-40. Recuperado: 07 mai. 2016. Disponível: http://www.scielo.br/scielo. php?pid=S0101-32622000000100003\&script=sci_arttext.

Souza, M. A. (2008). Educação do campo: Políticas, Práticas Pedagógicas e Produção Científica. Educação \& Sociedade, 29(105), 1089-1111. Recuperado: 24 abr. 2016. Disponível: http:// www.scielo.br/pdf/es/v29n105/v29n105a08.pdf.

Souza, M. A. (2012). Educação do campo: propostas e práticas pedagógicas do MST (2a ed). Petrópolis, RJ: Vozes.

Veer, R. V. D.; Valsiner, J. (1999). Vygotsky: uma síntese. São Paulo, Brasil: Edições Loyola.

Vigotsky, L. S. (2007). A formação social da mente: o desenvolvimento dos processos psicológicos superiores. São Paulo: Martins Fontes.

Vigotsky, L. S. (2010). A construção do pensamento e da linguagem. São Paulo: Martins Fontes.

Este trabalho foi produzido como um desdobramento do material obtido no âmbito de uma pesquisa de Doutorado.

Recebido: 21 de novembro de 2016 Aceito: 12 de fevereiro de 2018

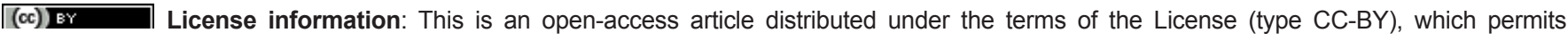
unrestricted use, distribution and reproduction in any medium, provided the original article is properly cited. 